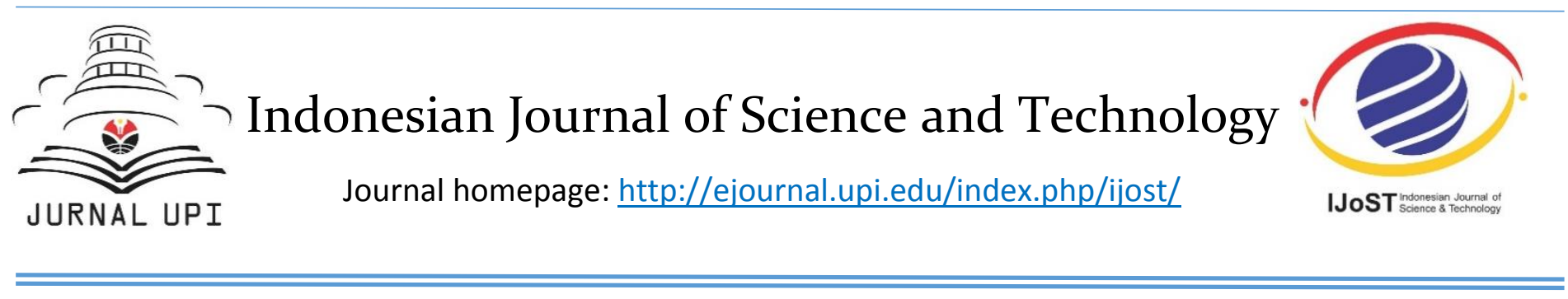

\title{
Carbon Nano Fibre Reinforcements In Concrete
}

\author{
Muhammad Maqbool Sadiq Awan ${ }^{1 凶}$, Parviz Soroushian ${ }^{2}$, Arshad Ali ${ }^{1}$, Muhammad Yousaf Saqid Awan ${ }^{1}$ \\ ${ }^{1}$ CE Wing, MCE, National University of Sciences and Technology, Islamabad, Pakistan \\ ${ }^{2}$ Department of Civil and Environmental Engineering, MSU, USA \\ *Correspondence: E-mail: aliarshad08@yahoo.com
}

\begin{abstract}
A B STRACT
Graphite nanomaterials offer distinct advantages over microscale reinforcing fibers in terms of engineering properties and geometric attributes. Through dispersion and effective interfacial interactions of proper functionalization of carbon nanofibers are the prerequisites for their effective use in high-performance cementitious matrices. Furthermore, the use of nano- and micro-scale reinforcements together provides reinforcing effects at different scales, thus rendering balanced gains in engineering properties of the matrix. However, their uses in coarser high-performance matrices have not been evaluated thoroughly. The results show improvements in all flexural attributes, impact and abrasion resistance of concrete with addition of $0.16 \%$ of oxidized and polyacrylic acid physisorbed carbon nanofibers, over the corresponding properties of plain matrix. The results also pointed to synergetic effects of hybrid reinforcements on improving the various engineering properties of DSP concrete matrix, especially with low modulus polypropylene microfibers.
\end{abstract}

\begin{tabular}{l}
\multicolumn{1}{c}{ A R T I C L E I N F O } \\
\hline Article History: \\
Submitted/Received 16 Oct 2016 \\
First revised 20 Aug 2018 \\
Accepted 28 Jan 2019 \\
First available online 31 Jan 2019 \\
Publication date 01 Apr 2019 \\
\hline Keywords: \\
Carbon Nano Fibre, \\
Reinforcements In Concrete, \\
Nanomaterials, \\
Cementitious matrices,
\end{tabular}

\section{INTRODUCTION}

Advanced technological aspects of cement based materials have recently focused on developing high-performance cementitious composites, which exhibit high compressive strengths. Such composites, however, exhibit also extremely brittle failure, low tensile capacity and appear sensitive to early age microcracking as a result of volumetric changes due to high autogenous shrinkage stresses. These characteristics of cement based materials are serious shortcomings that impose constrains in structural design and affect the long term durability of structures. To overcome the 
aforementioned disadvantages from the reinforcement of cementitious materials, it is typically provided at the millimeter and/or the micro scale using macrofibers and microfibers. Cementitious matrices, however, exhibit flaws at the nanoscale, where traditional reinforcement is not effective. Graphite Nanomaterials, including carbon nanofibers (CNFs), present several distinct advantages as a reinforcing material for high strength/performance cementitious composites as compared to more traditional fibers. First, they exhibit significant greater strength and stiffness than conventional fibers, which should improve overall mechanical behavior. Second, their higher aspect ratio is expected to effectively arrest the nanocracks and demand significantly higher energy for crack propagation. Third, CNFs are uniformly dispersed. Then, due to their nanoscale diameter, fiber spacing is reduced. This has opened a new field for nanosized reinforcements that should theoretically hinder the formation and later propagation of microcracks at the very beginning. Few attempts have been made to add different graphite nanomaterials as reinforcement in cementitious matrices.

Most of the works involving use of graphite nanomaterials in cementitious matrices have used very fine matrices to evaluate the efficiency of their reinforcement and reported modest gains in some of the engineering properties (Makar and Beaudoin, 2004; Makar and Chan, 2009; Li et al., 2005; Cwirzen et al., 2009; Cwirzen et al., 2008; Metaxa et al., 2009; Metaxa et al., 2010). A comprehensive approach was taken to evaluate suitably functionalized carbon nanofibers in high-performance cementitious materials of higher complexity, especially concrete. The results of functionalized and nonfunctionalized graphite nanomaterials in high performance
DSP paste and mortar matrices have been mentioned elsewhere (Alkhateb et al., 2013).

Based on previous studies (Awan et al., 2017; Asmara et al., 2018; Awan et al., 2017), the focus of this research paper is on the use of high-performance (DSP) concrete as the matrix in which the reinforcement efficiency of suitably functionalized carbon nanofibers and/ or different microfibers is evaluated. The larger aggregate size and content in concrete, when compared with mortar and paste, adds to complexity of behavior and failure modes by introducing an interfacial zone, generating interactions between aggregates and propagating microcracks, and the need to disperse nanomaterials in the space between aggregates.

Evaluation of the reinforcement efficiency of carbon nanofibers in a coarser cementitious matrix, high-performance concrete, was undertaken to see the effect of increased particle size on the interaction of nano reinforcements with the relatively coarser matrix. This has also highlighted the filler effect and dimensional stability brought about by use coarser aggregates in a well graded matrix. Furthermore, micro-scale fibers along with their hybrid combination with carbon nanofibers were evaluated to achieve desired balance of performance and cost efficiency.

Cementitious materials are essentially particulate composites, which are rarely used without aggregates (particulates). Given the micro- to millimeter-scale dimensions of the sand and gravel particles used in DSP concrete, hybrid reinforcements which complement the reinforcing and dimensional stabilizing actions of particulates with multiscale reinforcement mechanisms could produce particularly positive effects. In the past, the concept of using hybrid (micro- and millimeter-scale) reinforcement has been explored by the concrete industry for p- ISSN 2528-1410 e- ISSN 2527-8045 | 
achieving balanced gains in material properties (O'Connell et al., 2001; Banthia and Sappakittipakorn, 2007; MoranvilleRegourd, 2002; Lawler et al., 2005).

\section{MATERIALS AND METHODS}

\subsection{Materials}

Oxidized (CNF-OX) and polyacrylic acid physisorbed (CNF-PAA) carbon nanofibers, carbon microfibers (CMF) and polypropylene microfibers (PP) at different volume fractions were used in Densified with Small Particles (DSP) concrete matrix, as seen in Figure 1.

These carbon nanofibers have an outer diameters in the $60-150 \mathrm{~nm}$ range and lengths ranging from 30 to $100 \mu \mathrm{m}, 50-60$ $\mathrm{m}^{2} / \mathrm{g}$ specific surface area (SSA), $\sim 1.95 \mathrm{~g} / \mathrm{cm}^{3}$ true density, and $>95 \%$ purity. These pristine and oxidized nanofibers were purchased from Pyrograf Products, Inc. and PAA was physisorbed on to pristine nanofibers using a procedure described in the subsequent section. Carbon microfibers (CMF) with 6$\mathrm{mm}$ length and $6-\mu \mathrm{m}$ diameter were obtained from Toho Tenax America, Inc., US. Polypropylene microfibers (PP) with $19 \mathrm{~mm}$ in length and $39 \mu \mathrm{m}$ in diameter were obtained from New Nycon, Inc., US. Poly(acrylic acid) (PAA, average $M_{w}$ of about $100,000,35$ wt.\% of $\mathrm{H}_{2} \mathrm{O}$ ) was purchased from Sigma-Aldrich, US. Deionized (DI) water was used for all solution preparations and were purchased from PT Rumah Publikasi Indonesia, Indonesia.

\subsection{Dispersion of Nanotubes in Water}

The nanomaterial dispersion procedure comprised the following steps:

(1) Add the required amount of CNF-OX and CNF-PAA (carbon nanofibers and poly acrylic acid $1: 1$ by weight) to the mixing water of cementitious materials in order to achieve the targeted nanofiber volume fraction.
(2) Stir the mixture overnight (12 to 15 hours).

(3) Sonicate the mixture using a probe as follows: (i) Sonicate for ten minutes at different amplitudes (30\%, 45\%, 65\% and $75 \%$ ) with 1-minute breaks between different amplitudes; (ii) Pulse (1 minute on and 30 seconds off) for 10 minutes at $85 \%$ amplitude; (iii) Turn off the sonic probe for 2 minutes, and repeat the pulsing cycle two more times; and (iv) Repeat the whole sonic probing cycle one more time.

(4) For the microfiber and hybrid reinforcement systems, the microfibers were added to the mixing water without using the above dispersion procedure. Microfibers were added to the mixing water half an hour before mixing it with other ingredients of the DSP concrete in mixer.

\subsection{Cementitious Matrices}

Dense cement-based matrices with a smooth particle size gradation covering nano- to micro-scale range promise to effectively mobilize the tremendous mechanical qualities of graphite nanomaterials within cementitious nanocomposites. One category of cementbased matrices meeting these requirements is referred to as Densified with small particles (DSP). DSP cement-based materials comprise micro-scale cement and nano-scale silica fume particles, dispersed and densified with a superplasticizer, which is shown in Figure 2 (Guerrini, 2000).

Using this basic concept and introducing other ingredients (e.g., high-quality aggregates and discrete reinforcement), it is possible to obtain highly desired combinations of mechanical performance and durability suiting demanding fields of application (Guerrini, 2000). Based on a comprehensive review of the literature on DSP (Aïtcin, 2000; Badanoiu et al., 2003; 
Bayard and Plé, 2003; Bonneau at al., 1996; Bonneau et al., 2000; Chan and Chu, 2004; Cheyrezy et al., 1995; Dattatreya et al., 2007; Dili and Santhanam, 2004; Feylessoufi et al., 1996; Ju et al., 2007; Kaufmann and Hesselbarth, 2002; Lee et al., 2007; Matte and Moranville, 1999), the cementitious concrete matrix introduced in Table 1 was selected for evaluation of the merits of graphite nanomaterials and/or microfibers in cement-based materials.

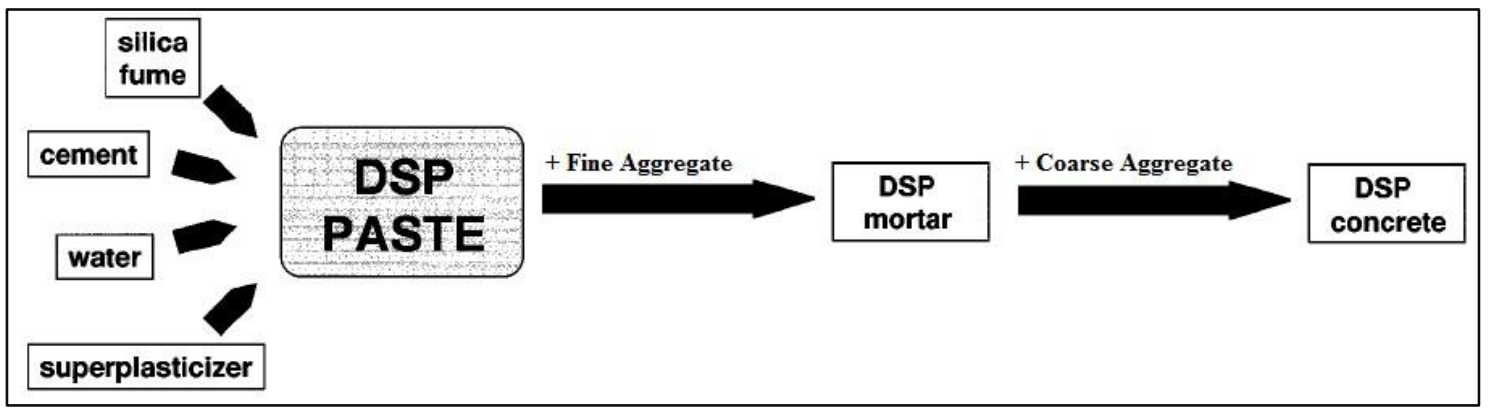

Figure. 1. DSP cementitious paste, mortar and concrete (Guerrini, G. L., 2000).
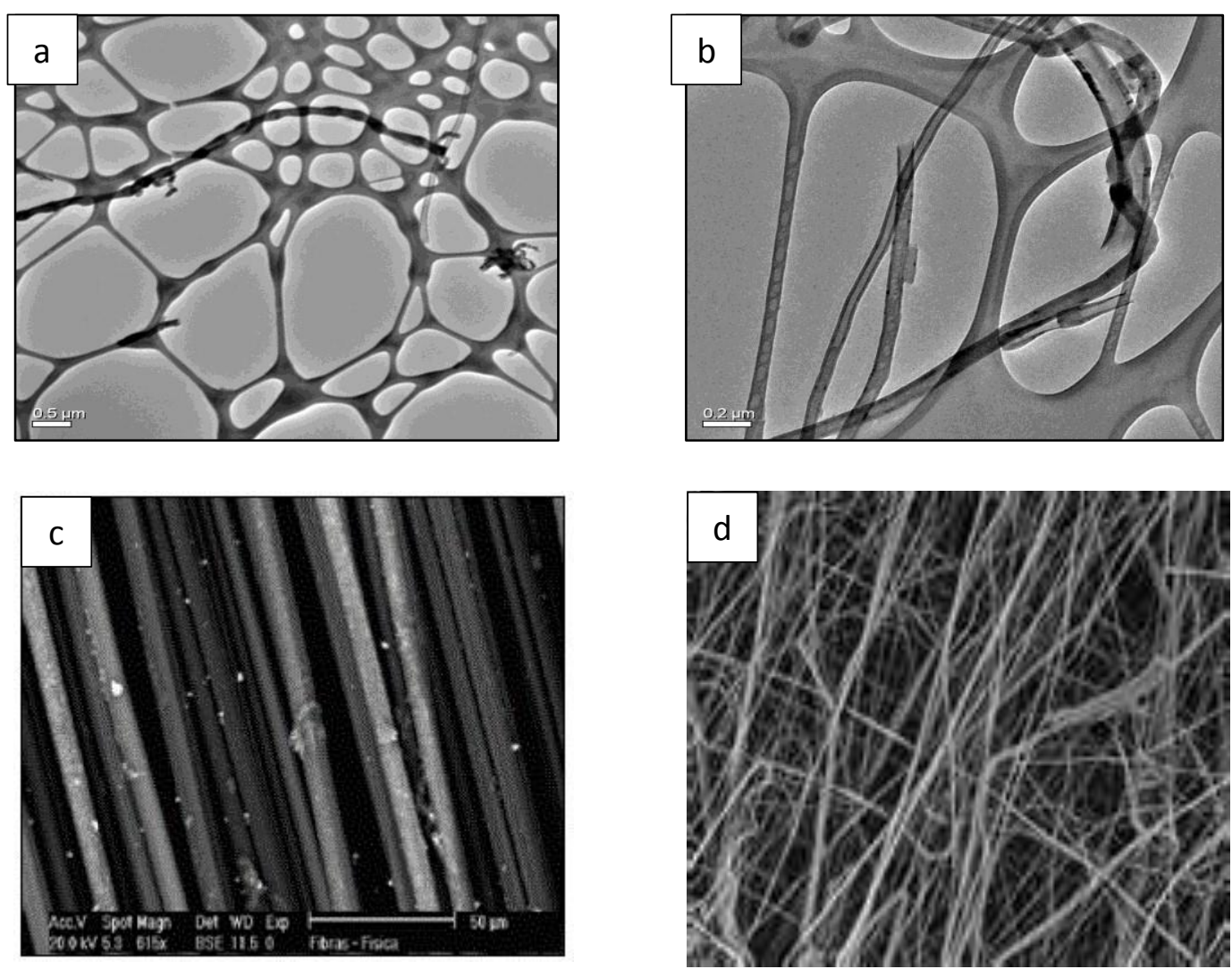

Figure. 2. TEM micrographs of CNF with OD of 8-15 $\mathrm{nm}$ and length of up to $50 \mu \mathrm{m}$, PAA physisorbed CNF-PAA (a); Oxidized nanofibers CNF-OX (b); SEM micrograph of carbon microfibers (TT 143) with $6 \mathrm{~mm}$ in length (c); and polypropylene microfibers (d). 
Table 1. Starting material selections and mix proportions (weight ratios) of high-performance cementitious concrete matrix.

\begin{tabular}{ll}
\hline Ingredient & DSP Concrete \\
\hline Silica Fume/Binder & 0.20 \\
Water/Binder & 0.20 \\
Superplasticizer/Binder & Adjusted for diff reinf \\
Silica Sand $(0-0.18 \mathrm{~mm}) /$ Binder & 0.36 \\
Silica Sand $(0.18-0.6 \mathrm{~mm}) /$ Binder & 0.86 \\
Granite Gravel $(1 \mathrm{~mm}-9 \mathrm{~mm}) /$ Binder & 0.50 \\
\hline
\end{tabular}

The materials selected for use in cementbased matrices included Type I Portland cement (Lafarge-North America), undensified silica fume (Norchem, Inc.) with the average particle size of $200 \mathrm{~nm}$, the specific surface area of $15 \mathrm{~m}^{2} / \mathrm{g}$, and minimum 7-day pozzolanic activity index of $105 \%$, silica sands (Fairmount Minerals) with average sizes of about 39 and $350 \mu \mathrm{m}$, comprising $>99.5 \%$ of silica, granite gravel ranging in sizes of from $1 \mathrm{~mm}$ to less than 9 $\mathrm{mm}$ (average particle size of $3.55 \mathrm{~mm}$ ). ADVA $^{\oplus}$ Cast 575 is a polycarboxylate-based Type F ASTM C 494 superplasticizer.

Cementitious materials (with and without carbon nanotubes and/or microfibers dispersed in the mixing water via sonication) were prepared using following the ASTM C 192 and C 305 procedures. The specimens were moist-cured inside molds after casting (ASTM C 192) over a 24-hour period, and were then demolded and subjected to 48 hours of steam curing at $70^{\circ} \mathrm{C}$. The samples were subsequently conditioned at $50 \%$ of relative humidity for seven days prior to testing. At least two batches were casted with at least four specimens for each test condition in each batch for all reinforcement conditions and engineering properties.

\subsection{Experimental Methods}

The test procedures employed to determine the engineering properties of cement-based materials are described in this section. Compression tests (ASTM C 109) were performed on $50 \mathrm{~mm}$ of cube specimens. Flexure tests (ASTM C 1185) were performed on $12.5 \times 50 \times 150 \mathrm{~mm}$ specimens by center-point loading on a span of $125 \mathrm{~mm}$ using a deflection-controlled mechanical test system, with load and deflection data collected using a data acquisition system. Impact tests (ASTM D 7136) were performed on $12 \times 150 \times 150 \mathrm{~mm}$ specimens. Abrasion tests (ASTM C 944) were conducted on the surface of cylindrical specimens with $100 \mathrm{~mm}$ in diameter (and $50 \mathrm{~mm}$ in height). Scanning electron microscopy (SEM) was also employed to gain further insight into the structure and failure mechanisms of cementbased nanocomposites. Experimental results were evaluated using the analysis of variance (ANOVA) and pair-wise comparison techniques. Response surface analysis (RSA) was used to identify reinforcement volume fraction, which provides optimum reinforcement and gains in various engineering properties of the cementitious matrix.

\section{RESULTS AND DISCUSSION}

Acid-oxidized (CNF-OX) and Poly-acrylic acid physisorbed (CNF-PAA) carbon nanofibers were used as reinforcement at 0.16 vol.\%; polypropylene (PP) and carbon microfibers (CMF) were used at 0.24 vol.\%. Combinations of polypropylene and carbon microfibers with PAA physisorbed carbon nanofibers were also used as hybrid reinforcement for concrete, with $\mathrm{PP} / \mathrm{CMF}$ 
microfibers and CNF-PAA used at 0.24 and 0.16 vol. $\%$, respectively.

\subsection{Flexural Performance}

The flexural attributes test results for the high-performance concrete reinforced with different volume fractions of carbon nanofibers and/or microfibers are summarized in Table 2. Significant gains in all flexural performance characteristics of concrete are observed with carbon nanofiber reinforcement used alone or in combination with microfibers. Polymer wrapping of nanofibers improves their reinforcement efficiency in concrete. The most desired balance of properties for a single reinforcement system was realized with 0.16 vol.\% of PAA-physisorbed carbon nanofibers (CNF-PAA). The corresponding improvements in flexural strength, energy absorption capacity and maximum deflection versus plain concrete were $20.9,134$, and $120 \%$, respectively.

Table 2. Mean values of flexural attributes of plain high-performance concrete and those reinforced with different nano- and/ or micro-scale reinforcement systems.

\begin{tabular}{|c|c|c|c|}
\hline Reinforcement Condition & $\begin{array}{l}\text { Flexural } \\
\text { Strength } \\
(\mathrm{MPa})\end{array}$ & $\begin{array}{l}\text { Deflection } \\
(\mathrm{mm})\end{array}$ & $\begin{array}{l}\text { Energy } \\
\text { Absorption } \\
\text { (N.mm) }\end{array}$ \\
\hline Plain & 13.4 & 0.71 & 92 \\
\hline Carbon microfiber, 0.24 vol.\% (CMF-0.24) & 12.8 & 1.01 & 111 \\
\hline Polypropylene microfiber, 0.24 vol.\% (PP-0.24) & 13.0 & 4.55 & 383 \\
\hline Carbon nanofiber, 0.16 vol.\% (CNF-0.16) & 15.4 & 1.52 & 193 \\
\hline Carbon nanofiber, 0.16 vol.\% (CNF-PAA-0.16) & 16.2 & 1.56 & 215 \\
\hline $\begin{array}{l}\text { Polypropylene microfiber, } 0.24 \text { vol.\% and Carbon nanofiber, } 0.16 \text { vol.\% } \\
\text { (CNF+PP) }\end{array}$ & 17.4 & 5.30 & 400 \\
\hline $\begin{array}{l}\text { Polypropylene microfiber, } 0.24 \text { vol.\% and Carbon nanofiber, } 0.16 \text { vol.\% } \\
\text { (CNF-PAA+PP) }\end{array}$ & 18.2 & 5.28 & 433 \\
\hline $\begin{array}{l}\text { Carbon microfiber, } 0.24 \text { vol.\% and Carbon nanofiber, } 0.16 \text { vol.\% } \\
\text { (CNF+CMF) }\end{array}$ & 17.2 & 1.55 & 274 \\
\hline $\begin{array}{l}\text { Carbon microfiber, } 0.24 \text { vol.\% and Carbon nanofiber, } 0.16 \text { vol.\% (CNF- } \\
\text { PAA+CMF) }\end{array}$ & 17.5 & 1.65 & 269 \\
\hline
\end{tabular}

The experimental data generated in the past pointed at the positive effects of hybrid (nano- and micro-scale) reinforcement systems in high-performance cementitious materials (Peyvandi et al., 2013). The test data presented here suggest that micro-scale fibers of lower modulus and lower cost (when compared with high-modulus carbon microfiber) could effectively complement the reinforcing effects of polymer-wrapped carbon nanofibers in high-performance (DSP) concrete. These lower-modulus microfibers, when used as hybrid reinforcement together with both treated and untreated carbon microfibers, produced balanced gains in the flexural performance attributes of the highperformance (DSP) concrete by interacting with and arresting the cracks developing in matrix at different scales. The hybrid reinforcement of low-modulus polymer (polypropylene) microfibers with nanofibers produced particularly pronounced gains in the mechanical properties of DSP concrete. The best balance of flexural attributes was realized with the hybrid reinforcing material comprising PAA-physisorbed carbon nanofibers (0.16 vol.\%) and polypropylene microfiber (0.24 vol.\%) (which were 
produced to have $35.8,644$, and $371 \%$ ) rise in the flexural strength, maximum deflection, and energy absorption capacity of the highperformance concrete.

The hybrid reinforcement systems also overcame the adverse effects of microfibers on flexural strength, as reported earlier. The synergistic reinforcing action of nano- and micro-scale reinforcement was further enhanced by polymer wrapping of carbon nanofibers. The effectiveness of hybrid reinforcement was also evident for highmodulus carbon microfibers when used with different PAA physisorbed carbon nanofibers. This hybrid reinforcement resulted in improvement of all engineering properties versus plain matrix and also versus a similar hybrid reinforced materials incorporating untreated carbon nanofibers.

The experimental results were subjected to statistical analysis of variance (ANOVA). Due to the large number of observations, ANOVA only gives the general trends in test results. The ANOVA outcomes indicate that there are statistically significant (at 0.05 significance level) improvements in all flexural attributes of high-performance concrete due to the addition of nano-scale and hybrid reinforcement systems. Pair-wise comparisons were carried out in order to assess the statistical significance of the effects associated with the addition of nanoand/or micro-scale reinforcement systems. These results indicate that nano-scale reinforcement systems at 0.16 vol.\% produced statistically significant improvements in all flexural attributes of the plain matrix at 0.05 of significance level when compared with plain concrete. Both microfibers produced statistically insignificant drops in flexural strength $(0.297$ and 0.481 of significance levels for carbon and polypropylene microfibers, respectively). Pair-wise analysis also pointed at statistically insignificant gains in energy absorption capacity (0.502 of significance level) and maximum deflection (0.402 of significance level) realized with 0.24 vol.\% of carbon microfiber. The use of low-modulus polypropylene microfiber as well as highmodulus carbon microfiber in conjunction with different surface functionalized carbon nanofibers reversed any negative trends in the effects of individual reinforcement, producing balanced gains in the engineering properties of high-performance DSP concrete at significance levels varying form 0.000 to 0.047 . The lower values of significance level were only for maximum deflection when carbon microfibers were used in conjunction with carbon nanofibers.

\subsection{Compressive Strength}

The compressive strength test results (mean values and standard errors) for highperformance concretes with nano- and/or micro-scale reinforcement systems are presented in Table 3. As was the case with DSP paste and mortar (Alkhateb et al., 2013), PAA physisorbed carbon nanofibers as well as both microfibers produced relatively small and statistically insignificant (at 0.05 of significance level) effects on the compressive strength of high-performance concrete.

Outcomes of pair-wise comparisons also indicate the effects of nano- and microscale reinforcement systems on compressive strength are not statistically significant (at 0.05 of significance level). The use of hybrid reinforcement systems comprising carbon or polypropylene microfiber and carbon nanotubes restored the compressive strengths of DSP concrete by inducing interactions with matrix and its cracks at different scales. The hybrid reinforcement system comprising functionalized carbon nanofibers and micro-scale polypropylene fiber produced a small rise in the compressive strength of high-performance concrete. 


\subsection{Impact Resistance}

The impact test data are summarized in Table 4. All nano- and/or micro-scale reinforcement systems produced improvements in the impact resistance of high performance concrete. The maximum rise in impact resistance realized with a single reinforcement $(69 \%)$ was for 0.16 vol.\% of CNTF-PAA. In the case of micro-scale fibers, polypropylene produced a higher gain $(60 \%)$ in the impact resistance of high-performance DSP concrete.
All hybrid nano- and micro-scale reinforcement systems produced further rise in the mechanical properties of highperformance concrete when compared with individual (nano- or micro-scale) reinforcement used alone. A significant ( 0.000 significance level) increase in impact resistance was observed for the hybrid reinforcement comprising polypropylene microfiber with CNF-PAA, which confirms the effectiveness of hybrid reinforcement.

Table 3. Mean values and standard errors of the compressive strength test results for plain DSP concrete and those reinforced with nano- and/ or microscale reinforcement systems.

\begin{tabular}{|c|c|c|}
\hline Reinforcement Condition & $\begin{array}{c}\text { Mean } \\
\text { Compressive } \\
\text { Strength } \\
(\mathrm{MPa})\end{array}$ & $\begin{array}{l}\text { Standard Error } \\
\qquad(\mathrm{MPa})\end{array}$ \\
\hline Plain & 151 & 7.75 \\
\hline Carbon microfiber, 0.24 vol.\% (CMF-0.24) & 139 & 13.5 \\
\hline Polypropylene microfiber, 0.24 vol.\% (PP-0.24) & 137 & 18.4 \\
\hline Carbon nanofiber, 0.16 vol.\% (CNF-0.16) & 140 & 8.75 \\
\hline Carbon nanofiber, 0.16 vol.\% (CNF-PAA-0.16) & 144 & 8.23 \\
\hline $\begin{array}{l}\text { Polypropylene microfiber, } \quad 0.24 \text { vol.\% } \quad \text { and } \\
\text { Carbon nanofiber, } 0.16 \text { vol.\% (CNF+PP) }\end{array}$ & 148 & 12.3 \\
\hline $\begin{array}{l}\text { Polypropylene microfiber, } 0.24 \text { vol.\% } \% \text { and } \\
\text { Carbon nanofiber, } 0.16 \text { vol.\% (CNF-PAA+PP) }\end{array}$ & 148 & 4.33 \\
\hline $\begin{array}{l}\text { Carbon microfiber, } 0.24 \text { vol.\% and Carbon nanofiber, } 0.16 \\
\text { vol.\% (CNF+CMF) }\end{array}$ & 150 & 9.87 \\
\hline $\begin{array}{l}\text { Carbon microfiber, } 0.24 \text { vol. } \% \text { and Carbon } \\
\text { nanofiber, } 0.16 \text { vol. } \% \text { (CNF-PAA+CMF) }\end{array}$ & 151 & 13.1 \\
\hline
\end{tabular}

The maximum increase in impact resistance (115\%) was brought about by hybrid use of 0.16 vol.\% of CNFPAA and 0.24 vol.\% of PP microfiber. Outcomes of ANOVA and pair-wise comparisons point at the statistical significant $(0.000$ to 0.012 significance levels) of nano- and/ or microscale reinforcement effects on the impact resistance of high-performance concrete. When compared with high performance cement paste and mortar (with nano-scale reinforcement), concrete (with nano-scale reinforcement) provides higher levels of impact resistance; this observation points at the well-known contributions of aggregates (in concrete) to the toughness of cementitious matrices.

\subsection{Abrasion Resistance}

The abrasion test results produced for high-performance concrete with different volume fractions of graphite nanomaterials 
and/ or microfiber reinforcement are summarized in Table 5.

As shown in Table 5, CNF-PAA at 0.16 vol.\% produced the greatest improvement (reaching 40.0\%) in the abrasion resistance of high-performance DSP concrete. All nanoand/or microscale reinforcement systems produced marked gains in the abrasion resistance of this high-performance concrete matrix, which were statistically significant at 0.05 of significance level. Outcomes of pairwise comparisons confirmed that each of the reinforcement conditions considered here produced statistically significant improvements in the abrasion resistance of high-performance concrete (with the value of significance levels ranging form 0.006 to $0.000)$.

\subsection{Response Surface Analysis}

The test data on high-performance concrete with nano- and/or micro-scale reinforcement systems was subjected to response surface analysis. The objective of this analysis was to identify optimum reinforcement conditions which maximize the benefits to specific engineering properties of high-performance concrete. This section presents optimization of concrete nanocomposites for enhancing specific engineering properties, and also for simultaneous enhancement of several engineering properties.

Table 5. Mean abrasion weight losses of DSP concretes with and without nano- and/ or micro-scale reinforcement systems.

\begin{tabular}{lc}
\hline \multicolumn{1}{c}{ Reinforcement Condition } & Loss of \\
\cline { 2 - 2 } Plain & Mass (grams) \\
Carbon microfiber, 0.24 vol.\% (CMF-0.24) & 1.50 \\
Polypropylene microfiber, 0.24 vol.\% (PP-0.24) & 1.15 \\
Carbon nanofiber, 0.16 vol.\% (CNF-0.16) & 1.05 \\
Carbon nanofiber, 0.16 vol.\% (CNF-PAA-0.16) & 0.97 \\
Polypropylene microfiber, 0.24 vol.\% and Carbon nanofiber, 0.16 vol.\% (CNF+PP) & 0.98 \\
Polypropylene microfiber, 0.24 vol.\% and Carbon nanofiber, 0.16 vol.\% (CNF-PAA+PP) & 0.99 \\
Carbon microfiber, 0.24 vol.\% and Carbon nanofiber, 0.16 vol.\% (CNF+CMF) & 0.99 \\
Carbon microfiber, 0.24 vol.\% and Carbon nanofiber, 0.16 vol.\% (CNF-PAA+CMF) & 1.00 \\
\hline
\end{tabular}

Response surface analysis (RSA) of the test data was conducted considering the volume fractions of nano- and micro-scale reinforcement systems as input variables. Flexural strength, energy absorption capacity, maximum deflection and impact resistance were used as response variables. The RSA process started with evaluating the effects of input variables on response variables, and was followed with desirability analyses considering means of response variables, using both canonical and ridge analyses.

| DOI: http://dx.doi.org/10.17509/ijost.v4i1.4140 I p- ISSN 2528-1410 e- ISSN 2527-8045
RSA conducted for each of the flexural strength, energy absorption capacity, maximum deflection and impact resistance test data indicated that an optimum reinforcement system comprising 0.12 vol.\% of CNFPAA and 0.24 vol.\% of PP microfiber maximizes subject properties. Optimal

Response for flexural strength as calculated to be $17.20 \mathrm{MPa}$ with $95 \%$ of confidence Interval (16.02 nd $18.18 \mathrm{MPa}$ ), Optimal Response for energy absorption capacity is $482.78 \mathrm{~N} / \mathrm{mm}$ with $95 \%$ of confidence Interval (336.69 and 508.86 
$\mathrm{N} / \mathrm{mm}$ ), Optimal Response for maximum deflection is $5.101 \mathrm{~mm}$ with $95 \%$ of confidence Interval $(4.79,5.41 \mathrm{~mm})$, and Optimal Response for maximum impact resistance is $2.90 \mathrm{~mm} / \mathrm{mm}$ with $95 \%$ of confidence Interval ( 2.75 and $3.63 \mathrm{~mm} / \mathrm{mm}$ ). All stationary points are saddle points which do not give a maximum but a general direction to follow in which targeted properties can be maximized.

The ridge analysis outcomes can be used to adjust the reinforcement condition for achieving further gains in engineering properties, shown in Table $\mathbf{6}$. The analyses for flexural attributes and impact resistance show that the current hybrid reinforcement is the appropriate combination to maximize these properties of the matrix.

Desirability analysis of test data was also conducted in order to identify reinforcement conditions which yield a desired balance of all the engineering properties considered here. Desirability analyses were conducted using mean values obtained through both canonical and ridge analyses. These outputs indicate that maximum values of all response variables can be achieved with $0.11 ; 0.12$ vol.\% CNF-PAA and 0.26; 0.24 vol.\% PP microfiber. These values are closer to what is being used as hybrid reinforcement in this high-performance concrete matrix.

Table 6. Outcomes of Ridge analysis of the flexural attributes and impact resistance test data for high performance concrete with nano- and/or microscale reinforcement (Ridge Analysis for Maximizing Flexural Strength)

\begin{tabular}{llllll}
\hline \multicolumn{3}{c}{ Coded Radius Estimated 95.00\% Confidence Interval } & \multicolumn{3}{c}{ Uncoded Factor Values } \\
& Response & Upper & Lower & CNF-PAA & PP \\
\hline 0.000 & 15.604 & 15.024 & 16.183 & 0.080 & 0.120 \\
0.100 & 15.847 & 15.264 & 16.429 & 0.088 & 0.123 \\
0.200 & 16.093 & 15.502 & 16.684 & 0.095 & 0.127 \\
0.300 & 16.344 & 15.739 & 16.949 & 0.103 & 0.131 \\
0.400 & 16.600 & 15.976 & 17.225 & 0.110 & 0.136 \\
0.500 & 16.861 & 16.212 & 17.511 & 0.111 & 0.141 \\
0.600 & 17.128 & 16.449 & 17.807 & 0.112 & 0.147 \\
0.700 & 17.400 & 16.686 & 18.115 & 0.113 & 0.152 \\
0.800 & 17.678 & 16.924 & 18.433 & 0.116 & 0.208 \\
0.900 & 17.963 & 17.164 & 18.762 & 0.118 & 0.225 \\
1.000 & 18.253 & 17.404 & 19.103 & 0.120 & 0.240 \\
\hline
\end{tabular}


Table 6 (continue). Outcomes of Ridge analysis of the flexural attributes and impact resistance test data for high performance concrete with nano- and/or microscale reinforcement (Ridge Analysis for Maximizing Flexural Strength)

(a) Flexural Strength

\begin{tabular}{l|l|l|l|l|l}
\hline \multicolumn{7}{l}{ Ridge Analysis for Maximizing Energy Absorption Capacity } \\
\hline Coded Radius & Estimated & \multicolumn{2}{l}{ 55.00\% Confidence Interval } & \multicolumn{2}{l}{ Uncoded Factor Values } \\
\cline { 3 - 6 } & Response & Upper & Lower & CNF-PAA & PP \\
\hline 0.000 & 282.779 & 256.693 & 308.865 & 0.080 & 0.120 \\
0.100 & 295.584 & 269.367 & 321.800 & 0.082 & 0.132 \\
0.200 & 308.239 & 281.635 & 334.843 & 0.084 & 0.143 \\
0.300 & 320.761 & 293.521 & 348.000 & 0.086 & 0.155 \\
0.400 & 333.167 & 305.059 & 361.276 & 0.087 & 0.167 \\
0.500 & 345.477 & 316.288 & 374.667 & 0.087 & 0.179 \\
0.600 & 357.712 & 327.254 & 388.171 & 0.098 & 0.191 \\
0.700 & 369.893 & 338.003 & 401.783 & 0.108 & 0.203 \\
\hline
\end{tabular}

Ridge Analysis for Maximizing Energy Absorption Capacity

Coded Radius Estimated $95.00 \%$ Confidence Interval| Uncoded Factor Values

\begin{tabular}{l|l|l|l|l|l} 
& Response & Upper & Lower & CNF-PAA & PP \\
\hline 0.800 & 382.042 & 348.582 & 415.501 & 0.117 & 0.215 \\
0.900 & 394.181 & 359.037 & 429.326 & 0.0119 & 0.228 \\
1.000 & 406.334 & 369.406 & 443.263 & 0.120 & 0.240 \\
\hline
\end{tabular}

(b) Energy Absorption Capacity

\begin{tabular}{|c|c|c|c|c|c|}
\hline \multicolumn{6}{|c|}{ Ridge Analysis for Maximizing Maximum Deflection } \\
\hline \multirow[t]{2}{*}{$\begin{array}{l}\text { Coded Ra- } \\
\text { dius }\end{array}$} & \multirow{2}{*}{$\begin{array}{l}\text { Esti- } \\
\text { mated } \\
\text { Response }\end{array}$} & \multicolumn{2}{|c|}{$\begin{array}{l}95.00 \% \text { Confidence Inter- } \\
\text { val }\end{array}$} & \multicolumn{2}{|c|}{ Uncoded Factor Values } \\
\hline & & Upper & Lower & CNF-PAA & PP \\
\hline 0.000 & 3.101 & 2.793 & 3.408 & 0.080 & 0.120 \\
\hline 0.100 & 3.296 & 2.987 & 3.605 & 0.082 & 0.132 \\
\hline 0.200 & 3.492 & 3.178 & 3.805 & 0.083 & 0.143 \\
\hline 0.300 & 3.687 & 3.366 & 4.008 & 0.085 & 0.155 \\
\hline 0.400 & 3.882 & 3.551 & 4.213 & 0.086 & 0.167 \\
\hline 0.500 & 4.076 & 3.733 & 4.420 & 0.088 & 0.179 \\
\hline 0.600 & 4.271 & 3.912 & 4.630 & 0.089 & 0.191 \\
\hline 0.700 & 4.465 & 4.089 & 4.841 & 0.091 & 0.202 \\
\hline 0.800 & 4.659 & 4.264 & 5.054 & 0.092 & 0.214 \\
\hline 0.900 & 4.853 & 4.437 & 5.268 & 0.109 & 0.226 \\
\hline 1.000 & 5.046 & 4.608 & 5.484 & 0.119 & 0.238 \\
\hline
\end{tabular}


Table 6 (continue). Outcomes of Ridge analysis of the flexural attributes and impact resistance test data for high performance concrete with nano- and/or microscale reinforcement (Ridge Analysis for Maximizing Flexural Strength)

(c) Maximum Deflection

\begin{tabular}{|c|c|c|c|c|c|}
\hline \multicolumn{6}{|c|}{ Ridge Analysis for Maximizing Impact Resistance } \\
\hline \multirow[t]{2}{*}{$\begin{array}{l}\text { Coded Ra- } \\
\text { dius }\end{array}$} & \multirow{2}{*}{$\begin{array}{l}\text { Esti- } \\
\text { mated } \\
\text { Response }\end{array}$} & \multicolumn{2}{|c|}{$\begin{array}{l}95.00 \% \text { Confidence Inter- } \\
\text { val }\end{array}$} & \multicolumn{2}{|c|}{ Uncoded Factor Values } \\
\hline & & Upper & Lower & CNTF-PAA & PP \\
\hline 0.000 & 2.500 & 2.375 & 2.625 & 0.080 & 0.120 \\
\hline 0.100 & 2.567 & 2.441 & 2.693 & 0.086 & 0.127 \\
\hline 0.200 & 2.633 & 2.506 & 2.761 & 0.092 & 0.135 \\
\hline 0.300 & 2.700 & 2.569 & 2.831 & 0.099 & 0.142 \\
\hline 0.400 & 2.767 & 2.631 & 2.902 & 0.105 & 0.150 \\
\hline 0.500 & 2.833 & 2.693 & 2.974 & 0.111 & 0.157 \\
\hline 0.600 & 2.900 & 2.752 & 3.048 & 0.117 & 0.165 \\
\hline 0.700 & 2.967 & 2.811 & 3.123 & 0.124 & 0.172 \\
\hline 0.800 & 3.034 & 2.868 & 3.199 & 0.130 & 0.180 \\
\hline 0.900 & 3.100 & 2.925 & 3.276 & 0.136 & 0.227 \\
\hline 1.000 & 3.167 & 2.979 & 3.355 & 0.120 & 0.240 \\
\hline
\end{tabular}

(d) Impact Resistance

\subsection{Scanning Electron Microscope Evaluation}

Failed surfaces of flexure and compression test specimens were evaluated under a high-precision scanning electron microscope (JOEL 7500F). All samples were coated with Osmium (Using Osmium Coater Neoc-AN, Meiwa Shoji) prior to SEM observations. Figure 3 shows SEM images of DSP concrete samples.

The density of the DSP matrix is apparent in Figures 3a and 3b. Figure $3 a$ also highlights the positive effective of coarser particles in the matrix like sand and gravel. Figures $3 c$ to $3 e$ points at the uniform dispersion of nanotubes and their bridging/pullout actions across a fine (nano-scale) crack within the cementitious matrix. Figures $\mathbf{3 f}$ and $\mathbf{3 g}$ present evidence of micro-fiber pullout from the matrix. Scanning electron microscope (SEM) observations of cementitious concrete matrices reinforced with hybrid reinforcement (carbon nanofibres and microfibres) also indicated that the presence of nanofibers in the matrix around micro-fibres enhanced the interaction of matrix with micro-fibres (Figure $\mathbf{3 g}$ ), thus benefiting the gains in matrix performance with hybrid reinforcement. This strong interaction of matrix with micro-fibres was not observed in samples reinforced with only micro-fibre reinforcement. These observations provide some insight into the synergistic action of nano- and micro-scale reinforcement systems in cementitious matrices. All these observations support the results of various engineering properties mentioned in earlier. 

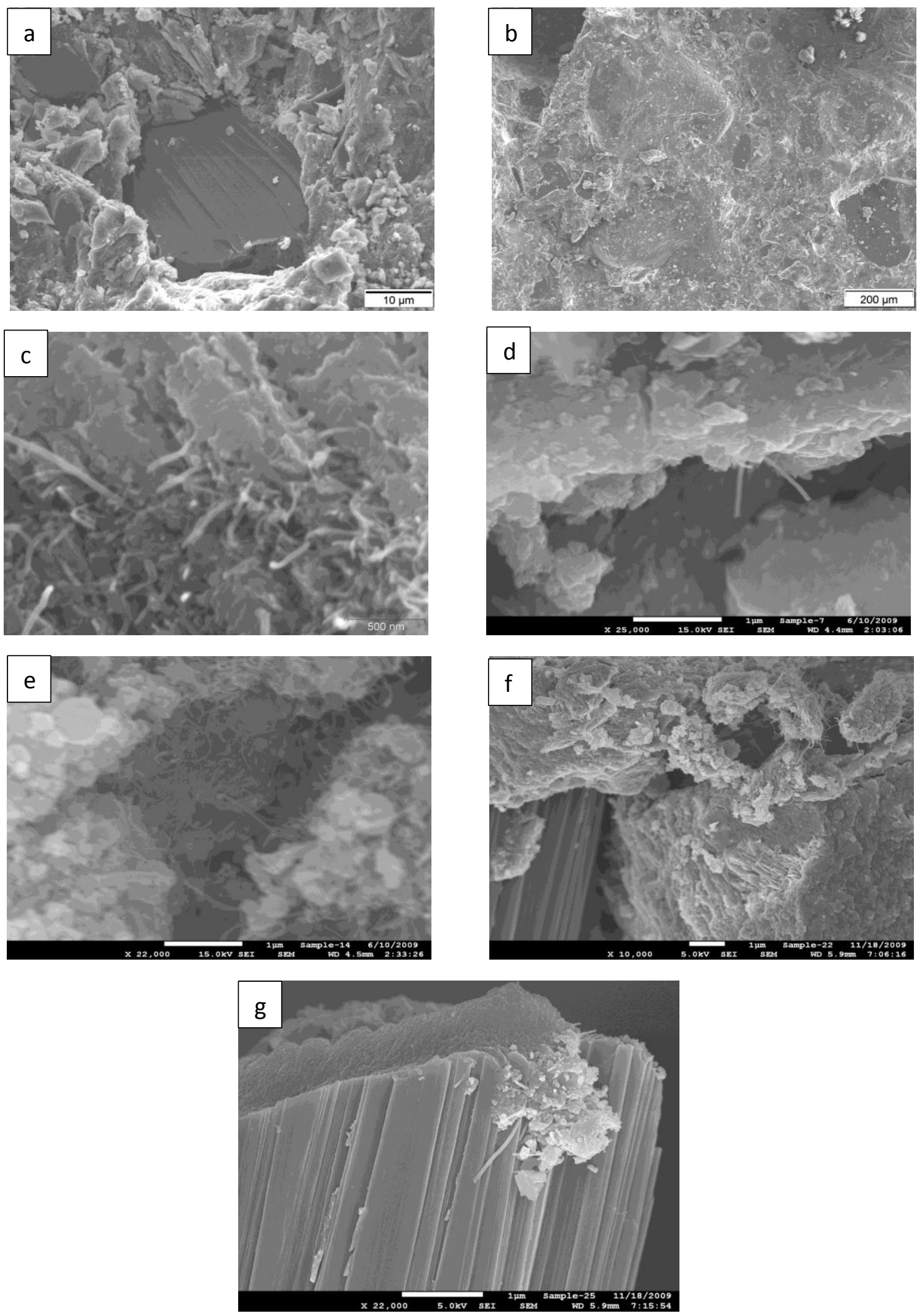

Figure 3. SEM images of sample: (a) crack deflection around sand particle; (b) dense structure of paste; (c) and (d) pulled out nanofibers at fractured surface; (e) distribution of nanofibers within the matrix (f) carbon microfibers in the matrix; and (g) carbon nanofibers interacting with carbon microfibers 


\section{CONCLUSIONS}

The experimental results generated for high performance cementitious concrete reinforced with both oxidized and (CNF-OX) PAA physisorbed carbon nanofibers (CNFPAA), polypropylene (PP) microfibers, carbon microfibers (CMF) and their hybrids casted at various/ optimum volume fractions and with carboxyl-based superplasticizers yield some conclusions, namely proper use of nano-scale reinforcement can produce improvements in high-performance concrete mechanical properties which surpass those realized with micro-scale reinforcement. Nano- and microscale reinforcement render complementary reinforcing effects in high-performance concrete. Among the individual reinforcement conditions evaluated in high performance concrete, CNF-PAA produces significant improvements in the mechanical properties of high-performance concrete. CNF-PAA act synergistically with micro-scale reinforcement towards enhancement of the mechanical properties of high-performance concrete. The refined hybrid reinforcement produced results which further demonstrated the synergetic action of nano- and micro-scale reinforcement systems. Statistical analyses, ANOVA and pair-wise comparison of test results generally confirmed the statistical significance of the results and trends identified.

\section{ACKNOWLEDGEMENTS}

This project was sponsored by the U.S. Army Contract \# W912HZ-08-C-0009. The authors are thankful to Richard Haskins for his support and feedback throughout the project. We also acknowledge Norchem, Inc, BASF and W. R.

Grace and Company for donating materials for the research.

\section{AUTHORS' NOTE}

The author(s) declare(s) that there is no conflict of interest regarding the publication of this article. Authors confirmed that the data and the paper are free of plagiarism.

\section{REFERENCES}

Aïtcin, P. C. (2000). Cements of yesterday and today: concrete of tomorrow. Cement and Concrete research, 30(9), 1349-1359.

Alkhateb, H., Al-Ostaz, A., Cheng, A. H. D., and Li, X. (2013). Materials genome for graphenecement nanocomposites. Journal of Nanomechanics and Micromechanics, 3(3), 67-77.

Asmara, Y. P., Kurniawan, T., Sutjipto, A. G. E., and Jafar, J. (2018). Application of Plants Extracts as Green Corrosion Inhibitors for Steel in Concrete-A review. Indonesian Journal of Science and Technology, 3(2), 158-170.

Awan, M. M. S., Soroushian, P., Ali, A., and Awan, M. Y. S. (2017). Use of Carbon Nano-Fibers in Cementitious Mortar. Indonesian Journal of Science and Technology, 2(2), 134-151.

Awan, M. M. S., Soroushian, P., Ali, A., and Awan, M. Y. S. (2017). High-Performance Cementitious Matrix using Carbon Nanofibers. Indonesian Journal of Science and Technology, 2(1), 57-75.

Badanoiu, A., Georgescu, M., and Puri, A. (2003). The study of'DSP'binding systems by thermogravimetry and differential thermal analysis. Journal of Thermal Analysis and Calorimetry, 74(1), 65-75. 
Banthia, N., and Sappakittipakorn, M. (2007). Toughness enhancement in steel fiber reinforced concrete through fiber hybridization. Cement and Concrete Research, 37(9), 1366-1372.

Bayard, O., and Plé, O. (2003). Fracture mechanics of reactive powder concrete: material modelling and experimental investigations. Engineering Fracture Mechanics, 70(7-8), 839-851.

Bonneau, O., Poulin, C., Dugat, M., and Tcin, P. C. A. (1996). Reactive powder concretes: from theory to practice. Concrete International, 18(4), 47-49.

Bonneau, O., Vernet, C., Moranville, M., and Aïtcin, P. C. (2000). Characterization of the granular packing and percolation threshold of reactive powder concrete. Cement and Concrete Research, 30(12), 1861-1867.

Chan, Y. W., and Chu, S. H. (2004). Effect of silica fume on steel fiber bond characteristics in reactive powder concrete. Cement and Concrete Research, 34(7), 1167-1172.

Cheyrezy, M., Maret, V., and Frouin, L. (1995). Microstructural analysis of RPC (reactive powder concrete). Cement and Concrete Research, 25(7), 1491-1500.

Collepardi M., Corinaldesi V., Monosi S., and Moriconi G., (2002). Applicazioni e sviluppo dei materiali DSP; DSP materials applications and development progress, Industria Italiana del Cemento, (72) 540-545.

Cwirzen, A., Habermehl-Cwirzen, K., and Penttala, V. (2008). Surface decoration of carbon nanotubes and mechanical properties of cement/carbon nanotube composites. Advances in Cement Research, 20(2), 65-73.

Cwirzen, A., Habermehl-Cwirzen, K., Nasibulin, A. G., Kaupinen, E. I., Mudimela, P. R., and Penttala, V. (2009). SEM/AFM studies of cementitious binder modified by MWCNT and nano-sized Fe needles. Materials Characterization, 60(7), 735-740.

Dattatreya, J. K., Harish, K. V., and Neelamegam, M. (2007). Use of particle packing for mix proportioning of reactive powder concrete. Indian Concrete Journal, 81(9), 31.

Dili, A. S., and Santhanam, M. (2004). Investigations on reactive powder concrete: A developing ultra high-strength technology. Indian Concrete Journal, 78(4), 33-38.

Feylessoufi, A., Villieras, F., Michot, L. J., De Donato, P., Cases, J. M., and Richard, P. (1996). Water environment and nanostructural network in a reactive powder concrete. Cement and Concrete Composites, 18(1), 23-29.

Guerrini, G. L. (2000). Applications of high-performance fiber-reinforced cement-based composites. Applied Composite Materials, 7(2-3), 195-207.

Ju, Y., Jia, Y., Liu, H., and Chen, J. (2007). Mesomechanism of steel fiber reinforcement and toughening of reactive powder concrete. Science in China Series E: Technological Sciences, 50(6), 815-832.

Kaufmann J., Hesselbarth D., (2002) Cementitious high performance composites, EMPA (Swiss Federal Laboratories for Materials Testing and Research) Publication, 32-33. 
Lawler, J. S., Zampini, D., and Shah, S. P. (2005). Microfiber and macrofiber hybrid fiberreinforced concrete. Journal of Materials in Civil Engineering, 17(5), 595-604.

Lee, M. G., Wang, Y. C., and Chiu, C. T. (2007). A preliminary study of reactive powder concrete as a new repair material. Construction and Building Materials, 21(1), 182-189..

Li, G. Y., Wang, P. M., and Zhao, X. (2005). Mechanical behavior and microstructure of cement composites incorporating surface-treated multi-walled carbon nanotubes. Carbon, 43(6), 1239-1245.

Makar, J. M., and Beaudoin, J. J. (2004). Carbon nanotubes and their application in the construction industry. Special Publication-Royal Society Of Chemistry, 292, 331-342.

Makar, J. M., and Chan, G. W. (2009). Growth of cement hydration products on single-walled carbon nanotubes. Journal of the American Ceramic Society, 92(6), 1303-1310.

Matte, V., and Moranville, M. (1999). Durability of reactive powder composites: influence of silica fume on the leaching properties of very low water/binder pastes. Cement and Concrete Composites, 21(1), 1-9.

Metaxa, Z. S., Konsta-Gdoutos, M. S., and Shah, S. P. (2009). Carbon nanotubes reinforced concrete. Special Publication, 267, 11-20.

Metaxa, Z. S., Konsta-Gdoutos, M. S., and Shah, S. P. (2010). Mechanical properties and nanostructure of cement-based materials reinforced with carbon nanofibers and polyvinyl alcohol (PVA) microfibers. Special Publication, 270, 115-124.

Moranville-Regourd, M. (2002). New cementitious systems and composite materials. Key Engineering Ceramics, 206, 1841-1846.

O'Connell, M. J., Boul, P., Ericson, L. M., Huffman, C., Wang, Y., Haroz, E., and Smalley, R. E. (2001). Reversible water-solubilization of single-walled carbon nanotubes by polymer wrapping. Chemical Physics Letters, 342(3-4), 265-271.

Peyvandi, A., Sbia, L. A., Soroushian, P., and Sobolev, K. (2013). Effect of the cementitious paste density on the performance efficiency of carbon nanofiber in concrete nanocomposite. Construction and Building Materials, 48, 265-269. 